\title{
Comparative Analysis of Different WEDM Strategies Applied to Cut WC-Co Cemented Carbides
}

\author{
Dariusz Poroś ${ }^{*}$ \\ ${ }^{1}$ Technical University of Wroclaw, 50370 Wroclaw, 27 Wyb. Wyspiańskiego Street, Poland \\ *Corresponding author's e-mail: dariusz.poros@pwr.edu.pl
}

\begin{abstract}
Cemented carbides WC-Co feature high mechanical properties and outstanding wear resistance. Traditional grinding of such hard workpiece features low material removal rate and diminished tool life. Notwithstanding that, even if, proper cooling fluid is applied; abrasive machining of cemented carbides characterizes poor efficiency. The aim of this study was to investigate the issue of WEDM of the cemented carbides WC-Co with two alternative materials of the wire electrodes applied. The presented experimental surface layer geometry measurements was carried out on a modern profilometer MITUTOYO SV 3200. Especially, WEDM results with wire flushing and in immersion were compared. Investigated were the effects of such input parameters as the pulse width and the time between two pulses on the output parameters such as area cutting efficiency, workpiece surface roughness in 2D and 3D. Analysing SEM microphotographs the surface layer defects after WEDM, cobalt depletion and pitting was discoursed. The analysed results provided WEDM of WC-Co cemented carbides with molybdenum wire electrode as seventy one percent less efficient and higher roughness was obtained for the same number of passes. The lowest height of the roughness on the surface after cutting with molybdenum wire amounted to Ra and $\mathrm{Sa}=3.5 \mu \mathrm{m}$. Such roughness involves a $25 \mu \mathrm{m}$ deep undesirable heat affected zone. WEDM with equal number of passes and brass wire resulted in roughness $\mathrm{Ra}$ and $\mathrm{Sa}=0.9 \mu \mathrm{m}$. In further research, an endeavour should be directed to examine different water and hydrocarbons derivative dielectrics impact on the surface layer structure and chemical composition of the machined WC-Co carbides.
\end{abstract}

Keywords: cemented carbides, wedm, roughness, wire electrodes.

\section{INTRODUCTION}

WEDM (Wire Electrical Discharge Machining) applications are still evolving. The main advantage of WEDM is capability of efficient cutting hard, brittle or slender workpieces with diminished risk of failure or deformation. Next benefit is low cost tool which geometry remains unaltered. Many cemented carbides applications often involve extreme mechanical demands at the surface. The most published researches investigate WEDM parameter optimization for cutting different hard to machine materials, dielectric environment modification or wire breakage elimination. Parameter optimization commonly is carried out for hard to machine materials or specific EDM applications. Cutting very hard cemented carbides or zirconia ceramics is one of many WEDM applications [1]. There are also many publications related to limitation of heat affected zone (HAZ) after electrical discharge machining. These works concern recrystallized material, changes of hardness or residual stresses in the surface layer and grain growth depth in to the bulk material.

In the research work [2] authors investigated surface morphology and stress distribution after electrical discharge machining of high strength aluminium alloys. The stresses proved to be a problem, specific for materials initially, plastically deformed. Measured stresses in aluminium alloys increased by heat generated during EDM. Authors of [3] analysed wire electrical discharge machining application for the generation of steel, form tool. Time parameters, voltage, electrode 
tension, flushing pressure were varied whereas tool geometry (clearance angle, included angle), surface roughness and MRR (Material Removal Rate) were the measured responses. Results have shown that pulse ON time and pulse off time as the two most significant factors for clearance angle, included angle, MRR and measured roughness.

In several publications a type of the dielectric environment was investigated. Commonly, there is comparative analysis of the results after electrical discharge machining with kerosene or distilled water [4]. One of the more original ideas, still only experimental is electrical discharge machining in gaseous atmosphere [5].

Wire failure is one of the most important issues which limit the increase of WEDM efficiency. Wear of the brass, consumable, electrode is not a problem as long as don't entail wire breakage [6]. The wire wear is mostly caused by amount of heat dissipated to the tool. Broken electrode results in increased machining time, marks on the machined surface and lost presupposed accuracy [7]. Wire analyses concern the crater's diameter and depth, as well as the permitted conditions in the (inter - electrode) gap. The relationship between amount of short circuits and wire braking has been already studied [8]. The increase of short circuits amount thirty milliseconds before causes wire damage. Authors in [9] studied influence of discharges frequency variability on wire breakage. Applied frequency changes detector was sensible only to one type of pulses generator. The sudden increase of frequency 5-40 ms before wire breaking was noticed. The thermal model of the electrical discharge machining process was proposed in publication [10] and [11] both needed to accept many restrictions. Calculations for proposed models were realized also by authors of [12] and the equation was improved by adding the heat transfer and energy distribution ratios between the wire electrode and the gap. For different dielectric, tools and workpiece materials, it is important to classify the process by classification of types of discharges occurring during machining [10]. The effect of the research [13] was establishing critical amount of temperature of the brass CuZn37 wire, resulting in wire breaking on $450 \mathrm{C}$. Vapour process of material of the electrode occurs in the first stage of discharge, up to $0.3 \mu \mathrm{s}$. Melting process of material of the wire takes more time and occur after $0.4 \mu$ s. Other research also proved electrode wire's material to be a significant factor affecting WEDM performance
[14]. Wire electrode material's electrical and thermal conductivity, melting temperature and tensile strength [15] occurred to be the most influential properties. There is the great interest for applications where precise, intricate and complex geometries are primary design requirements. Wire electrical discharge machine does not involve any physical contact between electrodes, therefore it can be performed regardless of the hardness and strength of the work-materials. However, it results in a heat affected zone on the outer layer with poor surface integrity, which can lead to mechanical defects of these materials. Thermal action of electrical discharge machining is known to yield a relatively poor surface integrity, including craters, micro - cracks and undesirable residual stresses [2] of the machined components.

This article concerns WEDM effects of the WC-Co cemented carbides collated by cutting with two alternative materials of the electrode. The first material of consumable, wire electrode is $\mathrm{CuZn} 37$ brass alloy, with a diameter of 0.25 $\mathrm{mm}$. Molybdenum wire with superior tensile strength and diameter of $0.18 \mathrm{~mm}$ was applied next. The author focuses on the study of surface integrity and if proper selection of the type of electrode and flushing techniques are capable to significantly influence on material features after WEDM. The objective of this investigation was to demonstrate impact of the time based parameters of WEDM process on appropriate machining results and whether WEDM of cemented carbides with molybdenum wire can be an option to $\mathrm{CuZn} 37$ wire electrode. Isotropicity of surface was depicted on 3D graphs of workpiece geometry. The advantages and restrictions of WEDM of WC-Co cemented carbides were discussed.

\section{WIRE ELECTRICAL DISCHARGE MACHINING OF WC-CO CEMENTED CARBIDES}

Author's [16] research was aimed at developing an optimal process energy source that produces improved material properties after WEDM. Researchers made simulation of the pulse waveforms and showed method for the thermal load of the cut surface reduction and the technical conditions adaptation to a particular application. In many applications, the WEDM of WC-Co is restricted by the resulting properties of the surface layer. The studies showed that it is significant to 
use the correct parameter selection for first pass and post-cuts. The most actuating variable of time parameters is the pulse duration, i.e. with pulse duration $<500 \mathrm{~ns}$, higher current magnitudes can also be used without problems. Owing to the use of a new process energy source, the increase of bending strength of average $30 \%$ was achieved.

Likewise, researchers [17] analysed surface state of cemented carbides after electrical discharge machining, with the peak current and pulse duration varied. It was found that the hardness of the surface was equal to the original hardness of the workpiece for all conditions of the experiment. Damaged layer on the workpiece characterizes decreasing concentration of WC grains from the bulk material to the surface layer. Heat affected zone (HAZ) depth and the average size and number of micro-cracks increased with the peak current and ON time. The HAZ and microcracks were reduced when the peak current and ON time were set properly.

In paper [18], a study on the corrosion of a workpiece of cemented carbide submerged in water for a long time during WEDM is investigated. Submerging cemented carbide in water for a long time causes the surface of the cemented carbide becomes brittle, because the cobalt which is the binder of cemented carbide is dissolved in the water. Such feasible WC-Co surface defects are shown on fig.1. The authors described a method to estimate the corrosion state on the cemented carbide. The corroded state of cemented carbide machined by an $\mathrm{AC}$ power generator and by a DC power generator was studied. The method, which uses a zinc plate as a sacrifice metal, is useful for preventing the corrosion of thin cemented carbide. Also, the method, which uses an external power supply of approximately $2 \mathrm{~V}$, is useful for preventing the corrosion of thin cemented carbide. But neither of them is sufficient to prevent the corrosion of thick cemented carbide with a narrow and deep slit. In like manner, caused by overheating, the wire wear, analyses concern both size of craters: their diameter and depth. Currently covered wire electrodes are becoming more popular. Especially zinc coated copper and brass wires. Molybdenum wires still play a significant role in WEDM of susceptible to wire material diffusion materials.

Authors of [5] investigated dry WEDM of cemented carbides with gaseous dielectric flushing. The experimental results revealed gaseous dielectric to be effective to eliminate cobalt depletion, but increased HAZ depth remained one of this process disadvantages.

Concluding WEDM of cemented carbides needs to use correct electrode, time and current parameters to avoid overheating of the cut surface, when residual stresses are induced in the rim zone generating cracks that run deep into basic material. It is important to reduce the time when WC-Co is submerged in the water during WEDM. It is also observed that the EDM conditions have no effect on the microstructures of the bulk workpiece material. This means that damage caused by EDM on the treated surface is limited to a certain depth only. However, it is observed that the depth of the damaged layer and the average length, width and number of micro-cracks increase with the peak current and pulse duration. The damaged layer and micro-cracks seem to disappear when the peak current and pulse duration were set at very low values.

\section{PLANNING THE EXPERIMENT}

Machines applied to WEDM can be distinguished into two alternative wire feed mechanism types. CNC high speed feed wire cut EDM
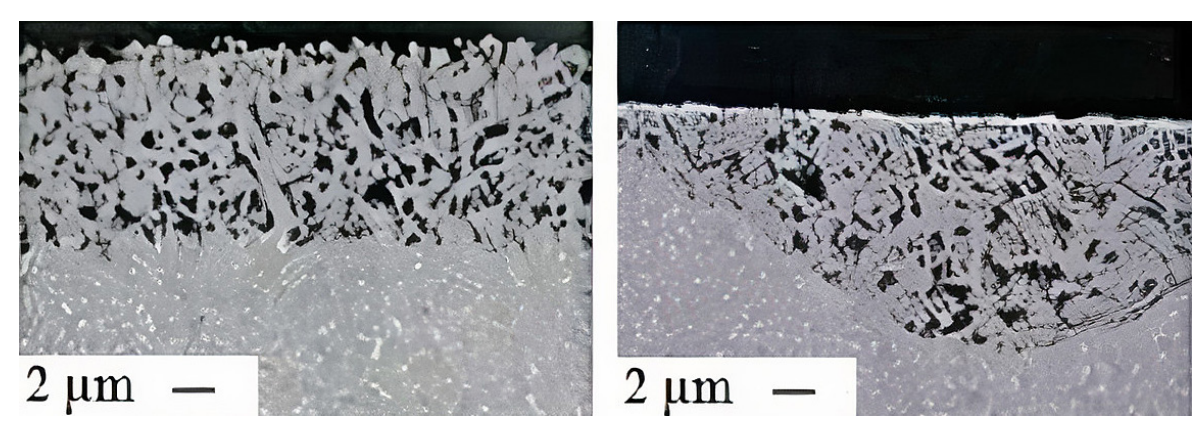

Fig. 1. Problems related to WEDM of cemented carbides a) pitting caused by long lasting contact with water, b) depletion of cobalt because of electrical discharge machining 


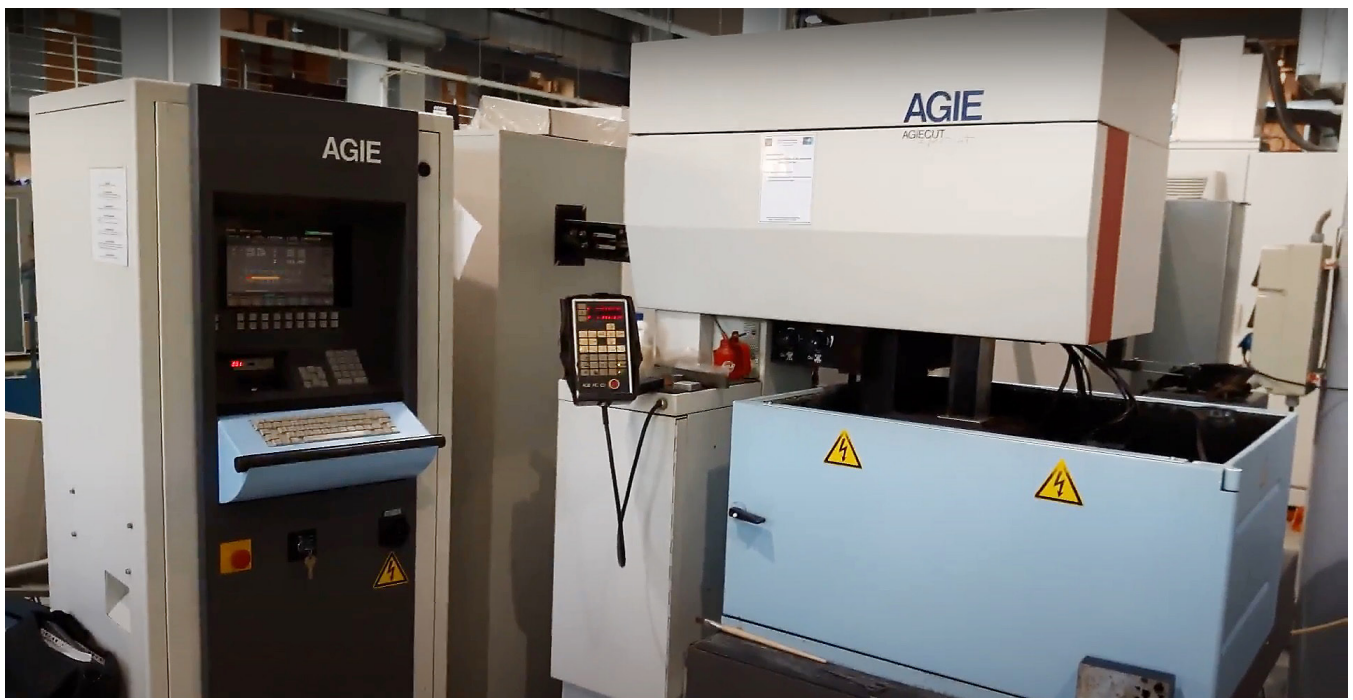

Fig. 2. AgieCut Sprint - main tank and programmable controller with CAD/CAM software

machines works with non-consumable high tensile strength wires. A second more popular type are CNC low speed feed wire cut EDM machines with disposable brass or copper wires, see Figure 2. In general, disposable, brass wire electrode moves steady, usually $0.2 \mathrm{~m} / \mathrm{s}$, to one direction. Wire electrode is consumable and is being replaced continuously after it's worn, works smoothly, with constant diameter, less vibration and excellent cutting accuracy. Such ordination is also geographically established in the market. This slow feed wire cut EDMs are mainly produced in Japan, Switzerland, applied for machining products with very strict requirement of accuracy and surface finish. High speed feed wire cut EDM machine, its wire feeds at increased speed, regularly $4-11 \mathrm{~m} / \mathrm{s}$ and wire travels repeatedly.

Main drawback of increased travelling speed of the wire is vibrations of the electrode, furthermore periodically changing direction of the wire travelling cause diminish of cutting quality. Increased speed of the travelling wire EDM machine idea is primary from China, and is successfully and widely applied on this market. Novelty of high electrode travelling speed EDM machines is programmable algorithm for more than rough cutting pass. Finish cutting passes were unique for the low speed feed machines. Owing to this refinement, surface roughness Ra after WEDM was decreased to lower than $1 \mu \mathrm{m}$.

The aim of the article required that three stages of the research were planned:
- Experiment planning with the central composite one and response surface methodology were applied for WEDM process modelling [20].

- The relationship between time parameters of the WEDM and MRR, also Ra indicator of surface roughness, for both types of machines and electrodes, were tested

- Surface roughness parameters according to ISO 25178 for cemented carbides WC-Co after WEDM was presented on 2D and 3D graphs and discussed.

\section{RESULTS AND DISCUSSION}

The workpiece geometry is shown in Figure 3. Characteristic of the material tested is presented in Table 2. Cut out in the process were parallelepipeds $5 \times 20 \times 30 \mathrm{~mm}$. Molybdenum wire is a very high strength wire (tensile strength $1830 \mathrm{MPa}$ ) and was applied at first. Since tensile strength, of the molybdenum electrode its main advantage is maintaining excellent wall straightness and reducing the number of wire-breaks in the contrary to brass wires (soft brass $375 \mathrm{MPa}$ and hard brass $900 \mathrm{MPa}$ ). The diameter $0.18 \mathrm{~mm}$ of the molybdenum wire is a perfect compromise between tool life, MRR, Surface roughness and cutting precision. Molybdenum electrode meets requirements of narrow kerfs and near-sharp, inside corner radii. Second electrode was disposable brass $\mathrm{CuZn} 37$ wire with a diameter of $0.25 \mathrm{~mm}$ and strength 900 $\mathrm{MPa}$. The properties of both wires adapted to the present experiment are given in Table 1. 
Table 1. Characteristic of the wire electrodes materials adapted in the experiment [19]

\begin{tabular}{|c|c|c|}
\hline Properties & \multicolumn{2}{|c|}{ Materials } \\
\cline { 2 - 3 } Melt. point, $[\mathrm{K}]$ & Molybdenum & 1183 \\
\hline Thermal conductivity, $\left[\frac{\mathrm{kg} \times \mathrm{m}}{\mathrm{s}^{3} \times \mathrm{K}}\right]$ & 2895 & 115 \\
\hline Electrical conductivity, $\left[\frac{\mathrm{s}^{3} \times \mathrm{A}^{2}}{\mathrm{~kg} \times \mathrm{m}^{3}}\right]$ & 138 & $16.2 \times 10^{6}$ \\
\hline Density, $\left[\frac{\mathrm{kg}}{\mathrm{m}^{3}}\right]$ & $18.7 \times 10^{6}$ & 8400 \\
\hline Tensile strength, $[\mathrm{MPa}]$ & 10220 & 480 \\
\hline Thermal expansion coefficient $\left[\mathrm{K}^{-1}\right]$ & 1830 & $21 \times 10^{6}$ \\
\hline
\end{tabular}

Experimental research included two stages, which are a consequence of the stated objectives:

- Finding the function of the analysed object in the form of a regression function determining the impact of time parameters on cutting surface efficiency and surface roughness after treatment, using the PS/DS-P program: $\lambda$, graphical presentation of the obtained dependences on WEDM time parameters [20].

- The effect of these factors on the depth of thermally changed layer was also studied using microscopic images. To reduce the number of necessary measurements, it was assumed that surface cutting performance and surface roughness significantly depend on: discharge time - ON $[\mu \mathrm{s}]$, pause time between discharges - OFF $[\mu \mathrm{s}]$.

Workpiece material is G20 cemented carbide with cobalt binder and medium grain size over 2 $\mu \mathrm{m}$. Due to a high toughness and excellent impact strength is commonly applied in a wide range of applications especially treatment of cast iron, steel, wood and paper. Most significant properties of machined cemented carbides are given in Table 2.

The height of the cut inserts was $5 \mathrm{~mm}$ and was constant during the experiment. The Ra parameter of roughness was selected as an exemplary indicator of surface layer finish. The surface roughness was analysed with Mitutoyo SV-3200 profilometer. Surface roughness of the machined cemented carbides was measured and presented on graphics. For each value of the analysed parameters, three specimens were measured.
Scanning electron microscopy imaging for HAZ analysis, after WEDM, was introduced.

\section{MRR OF THE WEDM}

MRR of the analysed machining process was determined as a cutting rate multiplied by workpiece height. The impact upon time parameters on areal efficiency was presented on Figure 4. Increase of ON time affects in enhanced MRR of WEDM with a brass wire. It was also found that longer time gaps in analysed scope had a beneficial effect on stability of the operation without compromising the efficiency. These results are convergent to other research [16]. Because of technical distinction, experiments with molybdenum wire were performed with prolonged ON time. This affects the amount of energy converted to discharges greater than for the brass wire. It is

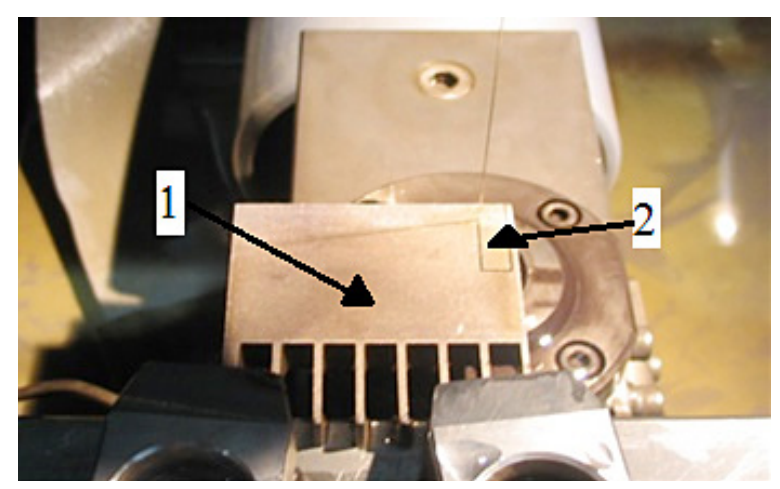

Fig. 3. Wire EDM machine workspace. Workpiece (1) with specimen shapes cut out (2)

Table 2. Properties of the machined material [19]

\begin{tabular}{|c|c|c|c|c|c|}
\hline Material & Composition & $\begin{array}{c}\text { Average Grain } \\
\text { Size }[\mu \mathrm{m}]\end{array}$ & $\begin{array}{c}\text { Thermal Conductivity } \\
{[\mathrm{W} / \mathrm{mK}]}\end{array}$ & $\begin{array}{c}\text { Thermal Expansion } \\
\text { Coefficient }\left[\mathrm{K}^{-1}\right]\end{array}$ & $\begin{array}{c}\text { Hardness } \\
\text { HV10 }\end{array}$ \\
\hline G20 & WC-11\%Co & 2.17 & 105 & $5.010^{-6}$ & 1200 \\
\hline
\end{tabular}



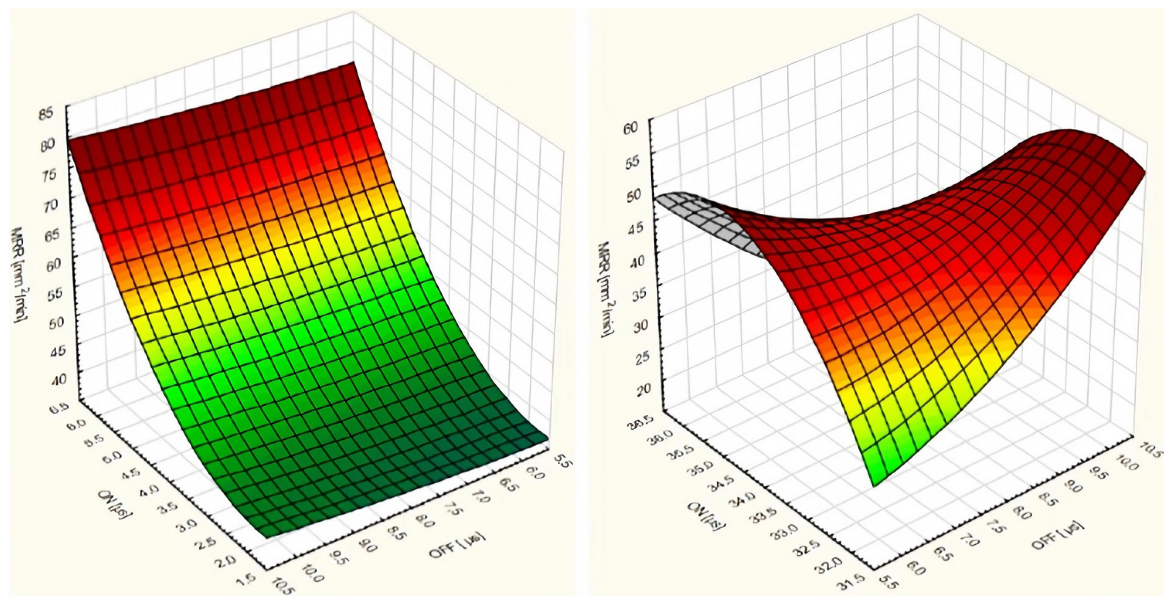

Fig. 4. Impact of time parameters of the WEDM on MRR of machined G20 cemented carbides:

a) brass electrode, b) molybdenum electrode

worth noting that high heat resistance of molybdenum wire resulted in much smaller volume of the spark craters discharged on the surface, than on the brass wire. Decreased volume of craters is less productive for gap flushing. Increased ON time beyond optimal flushing limit, there is a fall of a quantity of effective discharges. Increased OFF time in analysed scope is not enough efficient. Poor flushing is induced by molten material particles fulfilling the inter - electrode space.

\section{SURFACE LAYER}

The impact of ON/OFF times on surface roughness $\mathrm{Ra}$ was obtained through regression analysis and is presented on Figure 5. Extended ON time caused increased roughness for both of the wires. For higher energy discharges seems to be effective method of surface roughness improvement by increase OFF time to allow better inter-electrode gap flushing. The influence of time gap OFF on surface roughness is minor significant for both wire materials, but increased OFF time resulted in revised stability of the process. It is worth noting that Ra indicator measured for machining with molybdenum wire quickly reached the limit of efficient flushing of the (inter - electrode) gap and size of craters collapse even with prolonged discharge time. Roughness surfaces are presented on Figure 6. The lowest height of the roughness on the surface after cutting with molybdenum wire for $\mathrm{ON}=32 \mu \mathrm{s}$ and OFF $=6 \mu$ s was unsatisfactory and amounted to $\mathrm{Ra}$ and $\mathrm{Sa}=3.5 \mu \mathrm{m}$ (Fig. 6.a). Such roughness involves a deep, undesirable heat affected zone. However, shorter discharge time, $\mathrm{ON}=2$ $\mu \mathrm{s}$ and equally short $\mathrm{OFF}=6 \mu \mathrm{s}$ for brass wire
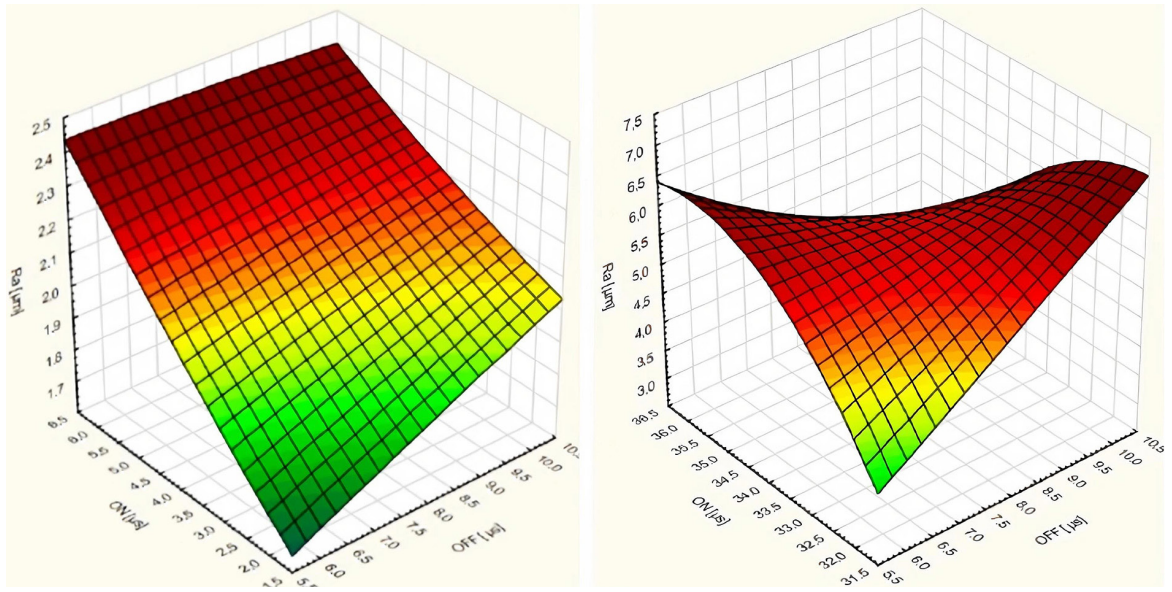

Fig. 5. Impact of time parameters of the WEDM on Ra indicator of surface roughness of machined G20 cemented carbides: a) brass wire, b) molybdenum wire 

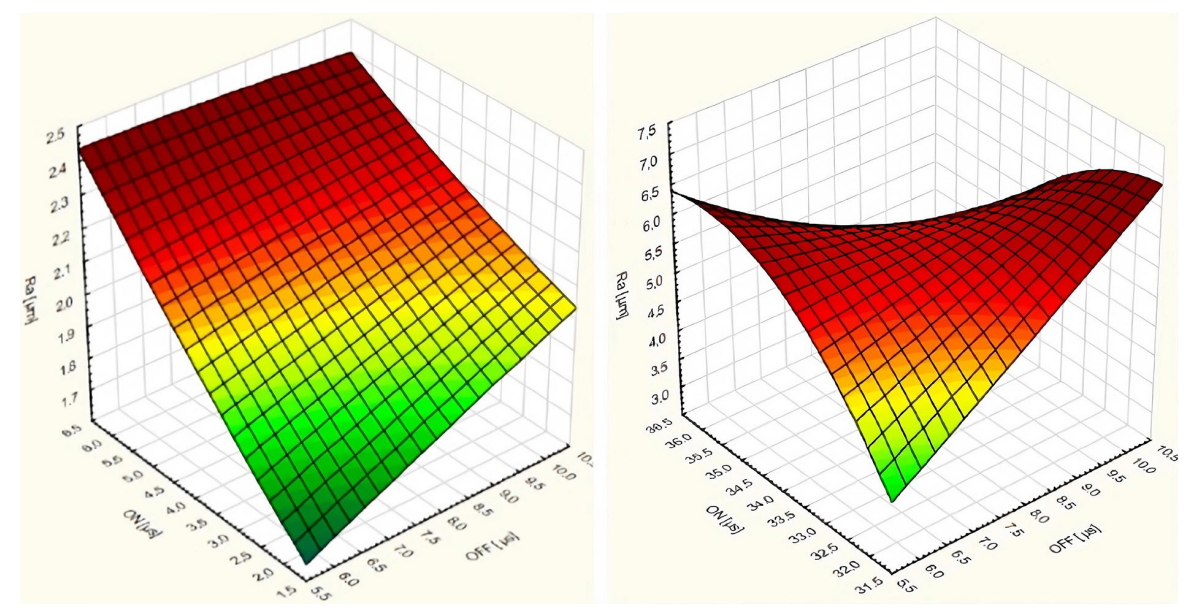

Fig. 6. The lowest roughness Sa surfaces of WEDM'ed cemented carbide G20 with: a) molybdenum wire, b) brass wire

resulted in roughness $\mathrm{Ra}$ and $\mathrm{Sa}=0.9 \mu \mathrm{m}$ (Fig. 6.b) and implies significantly reduced the heat affected zone. The worth to notice advantage of electro-discharge machining is isotropicity of the geometric structure (Fig. 6.) on the surface, especially important for applications when oriented texture is not allowed.

\section{HAZ ANALYSIS}

High temperature of discharges and rapid cooling by dielectric, result in the uneven heat dissipation in the machined surface of the workpiece. WEDM circumstances favour the formation of a recrystallized layer of molten material. The HAZ depth should be diminished - although in specific materials it is not a case - it is modifying workpiece structure and properties, by rise of hardness or residual stresses. More brittle, recrystallized cemented carbides layer, it may induce micro cracks to deepen. Authors [21] proved that the strength of cemented carbide (WC-30\%Co) was diminished about $35 \%$ compared to core material. Their study revealed that the surface characteristics was modified by micro - cracks, voids and pinholes. Once the overall discharge energy was increased surface became more rough by waste, craters and micro-cracks what was determined by SEM images. The issue of this study was to analyse methods of HAZ reduction to diminish residual stresses and eliminate risk of workpiece material damage. Surface layer before and after WEDM of cemented carbide G20 with visible craters and micro-cracks are presented on Figure 7. After Workpiece machining results is the stresses remained in the material, which can be desirable compressive or undesirable tensile. Generally, those tensile stresses have diminishing influence on e.g. the fatigue strength of the material. Compared to results in research [22] HAZ can be reduced to depth of about $2 \mu \mathrm{m}$. In this research the HAZ was recognized by the tungsten carbide grains concentration. The grains amount decreases continuously from bulk material to the machined surface layer. The WC grains are thinly dispersed in the damaged layer and dislodged during the WEDM process. Furthermore analysis revealed that, the bulk workpiece structure remained unaffected by WEDM conditions. Author agreed that WEDM does not entail structure modification to core material of the workpiece. The aim of this investigation of HAZ was to prove both the advantages of brass wire application and the possibility to decrease the depth of HAZ by proper time parameters' selection. WEDM with molybdenum electrode was less energy saving and generated more heat. The main disadvantage was lower flushing effectivity. MRR was less compared to brass wire. The analysis proved that the HAZ thickness after WEDM with a molybdenum wire is $25 \mu \mathrm{m}(\mathrm{ON}=32 \mu \mathrm{s}$ and $\mathrm{OFF}=6 \mu \mathrm{s})$, accordingly the application of a brass wire $(\mathrm{ON}=2 \mu \mathrm{s}$ and $\mathrm{OFF}=6 \mu \mathrm{s})$ permitted to diminish the HAZ thickness to $15 \mu \mathrm{m}$. The decreased HAZ is showed on Figure 8. Similarly in research [17] analysed the process parameters, among others, pulse duration throughout EDM of tungsten carbide piece of work. Analysis proved that for peak current and pulse duration $(I=16$ $\mathrm{A}$, and $\mathrm{t}=1.6 \mu \mathrm{s})$ no remarkable difference exists in the microstructures. Likewise in WEDM 

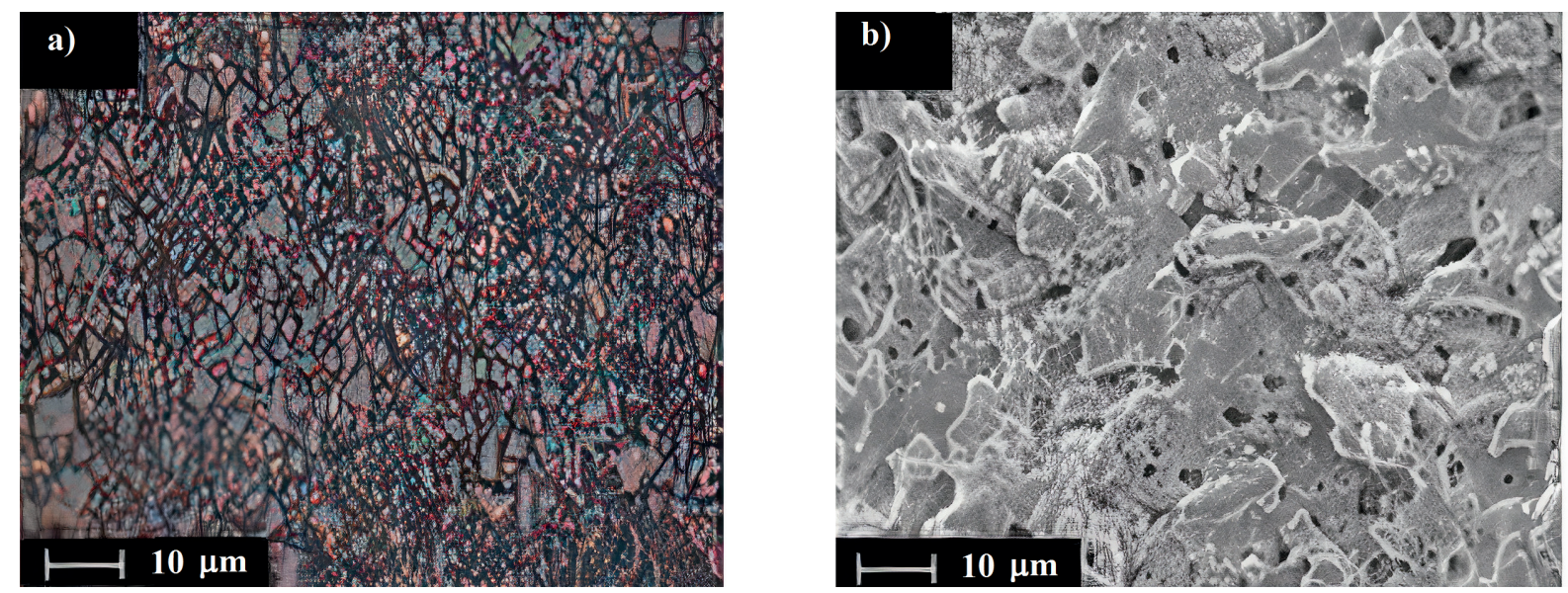

Fig. 7. Surface of the medium grains type, machined WC-Co cemented carbides G20: a) before WEDM, b) after WEDM
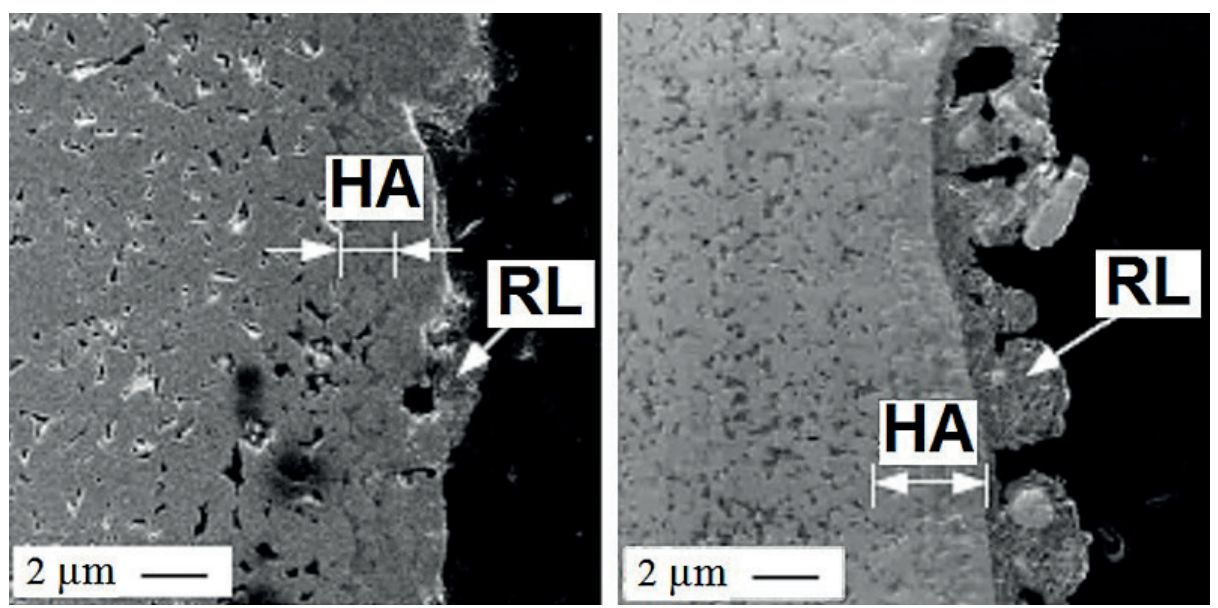

Fig. 8. Heat affected layer of machined G 20 cemented carbide: left - brass cutting, right- molybdenum cutting (HA-heat affected, RL-recast layer)

with molybdenum, when pulse duration is increased from $\mathrm{t}=1.6 \mu \mathrm{s}$ to $\mathrm{t}=12.8 \mu \mathrm{s}$ and $\mathrm{I}=16$ A an clearly damaged layer is seen to the depth of $15 \mu \mathrm{m}$ with more coarse WC grains, less Co and many craters and voids.

Current parameters and $\mathrm{ON}$ time, setting the quantity of heat transmitted to work space between electrodes, were both significantly increased for molybdenum electrode. Likewise, time gap has to be accordingly enhanced to pull out debris of the molten material from the gap. Flushing of the gap for molybdenum wire is more difficult. It is harder to pull out molten material particles from the gap cause of the lower volume of the craters on the surface of electrode. Temperature induced in the gap because of reduced flushing presumed to be elevated and influence on thicker heat affected layer under the surface of the workpiece. Working procedures can be related also to worse molybdenum wire WEDM results. Since it is not advisable to finish one part and then start working on the next one. It is much safer to do the rough cut on all parts, then the first finishing cut on all parts, etc. Otherwise, the first part cut (the component with the finished surface) will be exposed to water, and thus to the risk of corrosion, for a longer period. When the right procedure is observed, the risk of electrolysis can be greatly reduced. The author based on previous own experiments and analysed experiments attributes the result of HAZ decrease to the action of zinc vapour to diminish heat conductivity. This allows decreasing the penetration of heat into the workpiece [23]. Wires made of brass are the blend of zinc feature's low melting temperature $\left(420^{\circ} \mathrm{C}\right)$ and high sublimation pressure, with copper (melting point $1080^{\circ} \mathrm{C}$ ) in the CuZn37 alloy. The zinc from the alloy sublimates, which reduces the 
amount of molten particles released into the interelectrode gap. Instead of molten metal particles and evaporating dielectric, the gap is largely filled with a gas of zinc. Such gas has the lower thermal conductivity, lower than e.g. molten metals.

\section{CONCLUSIONS}

The introduced research on WEDM of G20 cemented carbides demonstrated valid impact of the time based parameters of WEDM process on appropriate machining results. Proper selection of the type of the electrode and flushing techniques are capable to significantly influence on material features after WEDM. The conducted studies enable the following conclusions to be drawn:

- MRR analysis corroborated benefits of WEDM with brass wire over cutting with molybdenum electrode. Calculated areal efficiency results proved to cut $71 \%$ faster with brass electrode.

- Increased time gap between discharges proved to aid strike a balance in the gap without noticeable decrease of efficiency. The break time between discharges should be long enough to allow debris removal from the gap.

- Achieved the finest finish of the surface was obtained for brass electrode $(\mathrm{Ra}=0.9 \mu \mathrm{m})$ and outperforms roughness accomplished with molybdenum wire $(\mathrm{Ra}=3.5 \mu \mathrm{m})$. Increase of discharge time improves MRR, but induces diminish of the surface finish irrespective of material of the wire.

- The worth to notice advantage of electrodischarge machining is isotropicity of the geometric structure of the surface, especially when oriented texture is undesirable

- Significant disadvantage of cutting with molybdenum wire is accompanied HAZ thickness $(25 \mu \mathrm{m})$. Total energy transferred to the gap when WEDM with molybdenum wire $\left(\mathrm{t}_{\mathrm{m}}=\right.$ $2625^{\circ} \mathrm{C}$ ) exceed energy, compared to cutting with brass electrode $\left(\mathrm{t}_{\mathrm{m}}=900-940^{\circ} \mathrm{C}\right)$.

- HAZ thickness for WEDM with brass wire electrode is diminished $(15 \mu \mathrm{m})$ even though increased MRR. Brass electrodes proved to be beneficial owing to vaporous zinc modifying thermal conductivity in the gap.

- Molybdenum collated to brass electrodes are resist to very high pulling forces. Furthermore, wear resistant molybdenum wire electrodes are profitable alternative electrodes. Modern, inexpensive wire flushing machines, with molybdenum electrodes, are capable to cut fair quality parts.

- Tensile strength of molybdenum electrode enables, by the faster travel through the workpiece, to remove more melted debris with him. High speed of travelling molybdenum wire provides superior flushing of the gap.

- The craters and micro - cracks on the surface of molybdenum wire are less volume, equated to wear marks on the brass electrode.

- Seems to be valid to investigate the relationship between process parameters and the effects of WEDM e.g. residual stresses and fatigue resistance in the next studies.

\section{Acknowledgements}

This work was financed from the funds of the Ministry of Education and Science by Agreement No. DNK/SP/513880/2021 of 22 December 2021, the project " $144^{\text {th }}$ School of Machining and the $43^{\text {rd }}$ Scientific School of Abrasive Machining", under the programme "Perfect Science".

\section{REFERENCES}

1. Matsuo T., Oshima E. Investigation on the optimum carbide content and machining condition for wire EDM of zirconia ceramics. Ann. CIRP. 1992; 41: 231-234.

2. Mehmood S., Sultan A., Anjum N.A., Anwar W., Butt Z. Determination of residual stress distribution in high strength aluminium alloy after EDM. Advances in Science and Technology Research Journal. 2017; 11(1): 29-35.

3. Ishfaq K., Mufti N.A., Ahmad J., Sajid M., Jahanzaib M. Analysis of the Effect of Wire Electric Dischage Machining Process Parameters for the Formation of High Speed Steel Form Tool. Advances in Science and Technology Research Journal. 2018; 12(1): 89-98.

4. Arshad R., Mehmood S., Shah M., Imran M., Qayyum F. Effect of Distilled Water and Kerosene as Dielectrics on Machining Rate and Surface Morphology of Al-6061 During Electric Discharge Machining. Advances in Science and Technology Research Journal. 2019; 13(3):162-169.

5. Yu Z., Jun T., Masanori K. Dry electrical discharge machining of cemented carbide, J. Mat. Proc. Technol. 2004; 149: 353-357.

6. Tosun N., Cogun C. An investigation on wire wear in WEDM, J. Mat. Proc. Technol. 2003; 134: 273-278.

7. Kunieda M., Takeshita S., Okumiya K. Study on wire electrode temperature in WEDM, Proceed. 
Int. Symp. For Electr. Mach. ISEM XII, Aachen. 1998: 119-128.

8. Tanimura T., Heuvelman C.J., Veenstra P.C., The properties of the Servo Gap Sensor with Wire Spark Erosion Machining, Ann. CIRP. 1977; 25: 59-63.

9. Kinoshita N., Fukui M., Gamo, G. Control of wire EDM preventing from breaking. Ann. CIRP. 1982; 31 .

10. Jennes M., Snoeys R., Dekeyser W. Comparison of Various Approaches to Model the Thermal Load on the EDM-Wire Electrode. Ann. CIRP. 1984; 33: 93-98.

11. Banerjee S., Prasad B.V.S.S.S., Mishra P.K. Analysis of three-dimensional transient heat conduction for predicting wire erosion in the wire electrical discharge machining process, J. Mat. Proc. Technol. 1997; 65: 134-142.

12. Rajurkar K.P., Wang W.M. Effect of thermal load on wire rapture in the WEDM, Transactions on the NAMRI/ASME. 1993; 20: 80-110.

13. Nowakowski A. Research on critical states of the WEDM process. Krakow Technology Institute, Scientific Papers, Krakow; 2004.

14. Prohaszka J., Mamalis A.G., Vaxevanidis N.M. The effect of electrode material on machinability in wire electro-discharge machining. J. Mat. Proc. Technol. 1997; 69: 233-237.

15. Luo Y. F. Rupture failure and mechanical strength of the electrode wire used in wire EDM. J. Mat.
Proc. Technol. 1994; 94 :208-215.

16. Juhr H., I in. Improved cemented carbide properties after wire-EDM by pulse shaping. J. Mat. Proc. Technol. 2004; 149: 178-183.

17. Hong Lee S.H., Li X. Study of the surface integrity of the machined workpiece in the EDM of tungsten carbide, J. Mat. Proc. Technol. 2003; 139: 315-321.

18. Obara H., Satou H., Hatano M. Fundamental study on corrosion of cemented carbide during wire EDM. J. Mat. Proc. Technol. 2004; 149: 370-375.

19. Poroś D., Zaborski S., Stechnij T. Analysis of WEDM application to cutting tools manufacturing for manual shaping of flat surfaces. AIP Conference Proceedings 2017, G20, 2018; 020023.

20. Polański Z. Optimization methods in machine technology. PWN Warsaw; 1997.

21. Kanagarajan D., Palanikumar K., Karthikeyan R. Effect of Electrical Discharge Machining on strength and reliability of WC-30\%Co composite, Journal of Materials and Design. 2012; 39: 469-474.

22. Parihar R.S., Sahua R.K., Srinivasua G. Effect of wire electrical discharge machining on the functionally graded cemented tungsten carbide surface integrity. Materials Today: Proceedings 5. 2018;28164-28169.

23. Poroś D., Zaborski S. Semi-empirical model of efficiency of wire electric discharge machining of hard-to-machine materials. J Mat. Proc. Technol. 2009;209:1247-1253. 